\title{
Implementasi Manajemen Transfer rate pada Proses HDFS Berbasis SDN
}

\author{
Narendra Hanif Wicaksana, F.X Arunanto, dan Hudan Studiawan \\ Jurusan Teknik Informatika, Fakultas Teknologi Informasi, Institut Teknologi Sepuluh Nopember (ITS) \\ Jl. Arief Rahman Hakim, Surabaya 60111 Indonesia \\ e-mail: anto@if.its.ac.id
}

\begin{abstract}
Abstrak-Pada cluster Hadoop perpindahan data akan sering terjadi, karena data yang disimpan akan tersebar ke dalam Datanode terutama pada saat melakukan proses penyimpanan ke dalam HDFS. Lalu lintas jaringan data mempengaruhi performa kinerja cluster Hadoop secara keseluruhan. Permasalahan ketersediaan bandwidth dan juga congestion yang disebabkan lalu lintas data lain dapat mempengaruhi proses penyimpanan data ke dalam HDFS. SDN memiiliki fungsi untuk melakukan pengaturan manajemen transter rate sehingga dapat mengkategorikan lalu lintas data dan juga menyediakan nilai transfer rate dengan menggunkan mekanisme queue. Memanfaatkan arsitektur jaringan SDN, pada cluster Hadoop dilakukan manajemen transfer rate untuk dapat mengoptimalkan proses perpindahan data pada saat penyimpanan ke HDFS. Manajemen transfer rate dilakukan dengan cara memanfaatkan fitur queue pada switch Openflow. Tiap queue digunakan untuk mengkategorikan lalu lintas data pada jaringan cluster Hadoop. Nilai transfer rate untuk lalu lintas data HDFS dipisahkan dan diberikan nilai transfer rate yang lebih tinggi. Berdasarkan hasil uji coba dengan melakukan manajemen transfer rate waktu proses penyimpanan data ke HDFS tidak terpengaruh walaupun pada saat proses penyimpanan data terdapat lalu lintas data lain yang mengakibatkan congestion.
\end{abstract}

Kata Kunci-Hadoop, HDFS, Openflow, Software Defined Networking, QoS.

\section{PENDAHULUAN}

$\mathrm{S}$ AAT berkembang arsitektur baru dalam mengelola jaringan yang dikenal sebagai Software Defined Networking [1]. Dimana kontrol jaringan yang sebelumnya berada pada tiap perangkat, dipindahkan menjadi terpusat. Ide Software Defined Networking muncul dari prinsip jaringan yang dapat diprogram (programmable network) sehingga konfigurasi perangkat jaringan menjadi lebih fleksibel, dinamis dan dapat diprogram. Hal tersebut dilakukan dengan cara mengambil alih proses penanganan paket (packet handling) dari yang sebelumnya dilakukan ditiap perangkat menjadi terpusat. Aristektur Software Defined Networking dibagi menjadi tiga komponen, yaitu infrastruktur, kontrol dan juga aplikasi. Konsep pada Software Defined Networking dapat mempermudah dan mempercepat inovasi pada jaringan.

Pada switch atau router saat ini data path dan juga control path berada pada perangkat yang sama. Switch Openflow memisahkan dua fungsi tersebut. Data path masih tetap berada pada switch sedangkan keputusan pemilihan rute dipindahkan ke controller terpisah. Ketika switch Openflow menerima paket yang baru diterima yang tidak berada pada alur masuk (flow entry), paket akan dikirimkan ke controller. Controller akan mengambil keputusan bagaimana menangani paket tersebut. Paket dapat di-drop atau dapat juga dimasukan ke dalam alur masuk switch, sehingga switch dapat mengetahui bagaimana jika mendapatkan paket yang serupa. Fitur lain yang dimiliki oleh Openflow adalah pengaturan transfer rate. Switch Openflow dapat melakukan pengaturan transfer rate dengan cara pembuatan queue.

Hadoop merupakan platform pengolahan big data. Hadoop menyediakan mekanisme penyimpanan data dan juga pengolahan data. Data-data pada cluster Hadoop disimpan pada sistem file yang dikenal dengan sebutan HDFS (Hadoop Distributed File System). Sedangkan pengolah data pada Hadoop menggunakan model pemograman MapReduce.

Pada cluster Hadoop perpindahan data akan sering terjadi, karena data yang disimpan akan tersebar ke dalam Datanode terutama pada saat melakukan proses penyimpanan ke dalam HDFS. Lalu lintas jaringan data mempengaruhi performa kinerja cluster Hadoop secara keseluruhan. Permasalahan ketersediaan bandwidth dan juga congestion yang disebabkan lalu lintas data lain dapat mempengaruhi proses penyimpanan data ke dalam HDFS.

Pada penelitian ini dengan memanfaatkan arsitektur jaringan SDN, pada cluster Hadoop dilakukan manajemen transfer rate untuk dapat mengoptimalkan proses perpindahan data pada saat penyimpanan ke HDFS. Manajemen transfer rate dilakukan dengan melakukan pengkategorian lalu lintas jaringan dan juga memanfaatkan fitur queue pada switch Openflow. Tiap queue yang dibuat dapat diatur nilai maksimum dan juga nilai minimum transfer rate. Dengan menetapkan nilai transfer rate pada cluster Hadoop maka lalu lintas untuk proses penyimpanan data ke HDFS terbebas dari congestion yang disebabkan dari lalu lintas data lain dan juga ketersedaian bandwidth.

\section{DASAR TEORI}

\section{A. Hadoop Distributed File System}

HDFS (Hadoop Distributed File System) [2] adalah file sistem distribusi untuk menyimpan dan juga mengolah data pada satu cluster Hadoop. Dalam mekanisme penyimpanan HDFS terdapat satu node pusat yang disebut Namenode yang 
menyimpan metadata dari sistem file dan juga node yang lainnya yang disebut sebagai Datanode. File dalam HDFS dipecah menjadi blok-blok data yang lebih kecil, biasanya bernilai $64 \mathrm{MB}$ tiap blok dan dapat juga diatur sesuai dengan keinginan. Tiap blok data akan disimpan secara terpisah pada Datanode dan akan direplikasi sesuai dengan pengaturan. Klien HDFS menghubungi Namenode untuk mendapatkan informasi lokasi tiap blok data.

\section{B. SDN dan Openflow}

Software Defined Networking (SDN) muncul dari prinsip jaringan yang dapat diprogram (programmable network) [3]. Ide SDN muncul untuk mencoba memenuhi kebutuhan konfigurasi perangkat jaringan sehingga menjadi lebih fleksibel dan juga dinamis. Hal tersebut dilakukan dengan cara mengambil alih proses penanganan paket (packet handling) dari yang sebelumnya dilakukan di tiap perangkat menjadi terpusat.

Terdapat tiga komponen dasar dalam SDN, dimana diantara tiap komponen terdapat antarmuka. Komponen pertama adalah aplikasi (application layer/ application plane). Aplikasi berada pada lapisan paling atas, aplikasi-aplikasi SDN berada pada bagian aplikasi, beberapa aplikasi dapat saling berjalan dan berkolaborasi satu sama lain. Aplikasi-aplikasi ini berkomunikasi dengan controller menggunakan API, API ini sering disebut sebagai Northbound Interface atau juga sering disebut dengan NBI.

Komponen kedua adalah controller (control layer/ controller plane). Controller SDN akan menerjemahkan kebutuhan aplikasi dengan infrastruktur dengan memberikan instruksi yang sesuai untuk SDN datapath serta memberikan informasi yang relevan dan dibutuhkan oleh lapisan aplikasi.

Komponen ketiga adalah infrastruktur (infastructure layer/ data plane). Terdiri dari elemen-elemen jaringan yang dapat mengatur SDN datapath sesuai dengan instruksi yang diberikan oleh controller. Control plane mengirim intruksi ke infrastructure layer melalui antarmuka yang disebut dengan Soutbound interface.

Dalam arsitektur SDN protokol Openflow merupakan salah satu elemen terpenting. Protokol Openflow [4] digunakan untuk berkomunikasi antara controller dengan switch Openflow atau yang disebut dengan atau yang disebut southbound interface. Protokol ini dapat mengubah flow table dari switch Openflow. Ketika switch Openflow menerima paket, switch akan mencoba mencocokan nilai header dari paket dengan aturan yang telah ada pada flow table. Apabila paket tidak ditemukan pada flow table maka switch Openflow, akan mengirimkan ke controller. Controller akan mengambil keputusan bagaimana menangani paket tersebut. Paket dapat di-drop atau dapat juga dimasukan kedalam flow table switch, sehingga berikutnya switch dapat mengetahui bagaimana jika mendapatkan paket yang serupa.

Selain fitur tersebut switch Openflow memiliki fitur pengaturan QoS. Pengaturan QoS pada switch Openflow dilakukan dengan mekanisme queuing. Tiap queue dapat digunakan untuk mengkategorikan jaringan sesuai dengan karakteristik jaringan yang dibutuhkan. Selain itu juga tiap queue yang dibuat dapat diatur nilai maksimum dan juga nilai minimum transfer rate.

\section{PERANCANGAN}

\section{A. Arsitektur Jaringan SDN}

Arsitektur jaringan SDN memiliki tiga komponen utama yaitu infrastruktur, controller, dan juga aplikasi. Ketiga komponen harus diimplementasikan untuk membagun arsitektur jaringan SDN. Salah satu permasalahan dalam pengimplementasian arsitektur jaringan SDN adalah dibutuhkan switch yang dapat mendukung protokol Openflow. Untuk menyiasati hal tersebut dibangun switch Openflow menggunakan low cost embedded Linux machine Raspberry Pi dan juga Open vSwitch yang pernah juga dilakukan pada penelitian sebelumnya [5].

Pada bagian infrastruktur digunakan Raspberry Pi yang telah diinstal dengan Open vSwitch sehingga dapat dijadikan sebagai switch Openflow. Untuk menambah jumlah antarmuka Ethernet pada Raspberry Pi digunakan adaptor USB to Ethernet.

Bagian Controller yang merupakan otak dari jaringan SDN digunakan Ryu [6]. Dengan menggunakan Ryu, controller dan juga switch dapat berinteraksi dengan menggunakan protokol Openflow dan juga OVSDB.

Pada bagian aplikasi, untuk mendukung platform SDN yang dibangun, digunakan aplikasi untuk menghubungkan antar host, switch hub, router dan juga aplikasi pengaturan transfer rate.

\section{B. Cluster Hadoop}

Cluster Hadoop dibangun terdiri dari dua node,yang terdiri dari satu Namenode dan satu Datanode. Node yang digunakan pada cluster yang dibangun menggunakan perangkat keras Raspberry Pi dan menggunakan Hadoop versi 1.2.

\section{Topologi Hadoop dan SDN}

Cluster Hadoop memiliki arsitektur master-slave dan SDN memiliki tiga komponen dalam arsitekturnya. Switch Openflow akan menjadi switch penghubung antara master dan juga slave pada cluster Hadoop seperti yang dapat dilihat pada Gambar 1. Datanode dan juga Namenode akan terhubung dengan port Openflow sedangkan switch Openflow akan terhubung dengan controller SDN melalui bukan port Openflow.

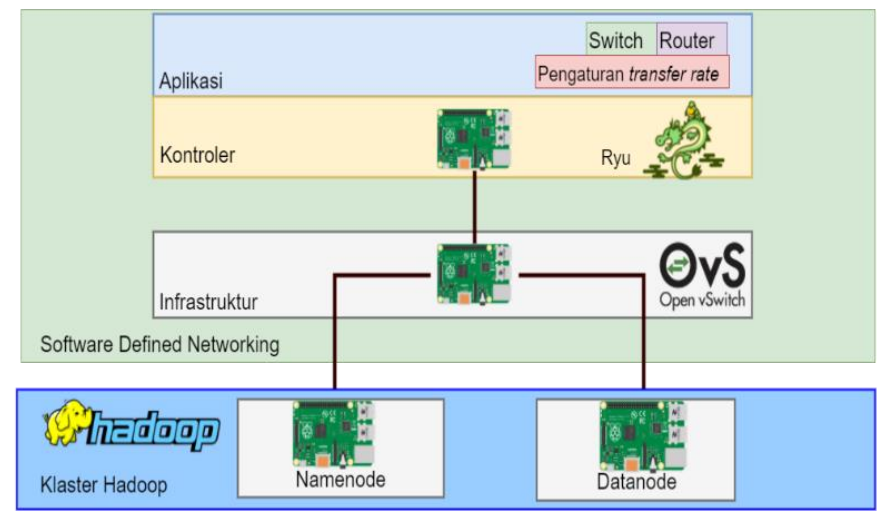

Gambar 1.Topologi Hadoop dan SDN

\section{Manajemen Transfer rate}

Pada kaster Hadoop yang dibangun akan dilakukan manajemen transfer rate sehingga proses HDFS Hadoop 
dapat dioptimalkan. Manajemen transfer rate dilakukan dengan cara memanfaatkan fitur yang dimiliki switch Openflow. Switch Openflow memiliki fitur pengaturan transfer rate dengan menggunakan mekanisme quеие. Dilakukan pengkategorian lalu lintas data dengan menggunakan quеие. Qиеие untuk proses penyimpanan data ke HDFS dipisahkan dengan lalu lintas data yang lain pada jaringan yang dibangun dan juga diberikan nilai transfer rate yang lebih besar dibandingkan dengan lalu lintas data yang lain. Sehingga ketika terjadi congestion pada jaringan proses perpindahan data HDFS tidak terganggu dan bandwidth tersedia. Pengaturan transfer rate pada klster Hadoop juga pernah dilakukan pada [7] untuk proses MapReduce.

\section{UJI COBA DAN EVALUASI}

Pada pengujian dilakukan penyimpanan data ke HDFS. Uji coba dilakukan pada cluster Hadoop yang yang terdiri dari satu Namenode dan satu Datanode yang saling terhubung dengan switch Openflow seperti yang dapat dilihat pada Gambar 2. Untuk dapat melihat pengaruh manajemen transfer rate, pada cluster Hadoop diberikan traffic tambahan untuk bertujuan membuat congestion sehingga proses perpindahan data menjadi terganggu. Traffic tambahan dilakukan dengan menjalankan program Iperf. Datanode dijadikan sebagai Iperf server yang akan menerima kiriman paket data dari klien Iperf seperti yang dapat pada Gambar 2. Pada pengujian dilakukan tiga skenario uji coba untuk melihat pengaruh dari manajemen transfer rate apabila terdapat traffic data lain yang mengakibatkan congestion pada cluster Hadoop. Tiap skenario dibandingkan waktu proses penyimpanan ke HDFS. Dataset yang digunakan terdapat tiga ukuran yaitu $1 \mathrm{MB}, 10 \mathrm{MB}$ dan $20 \mathrm{MB}$.

\section{A. Skenario Uji Coba 1}

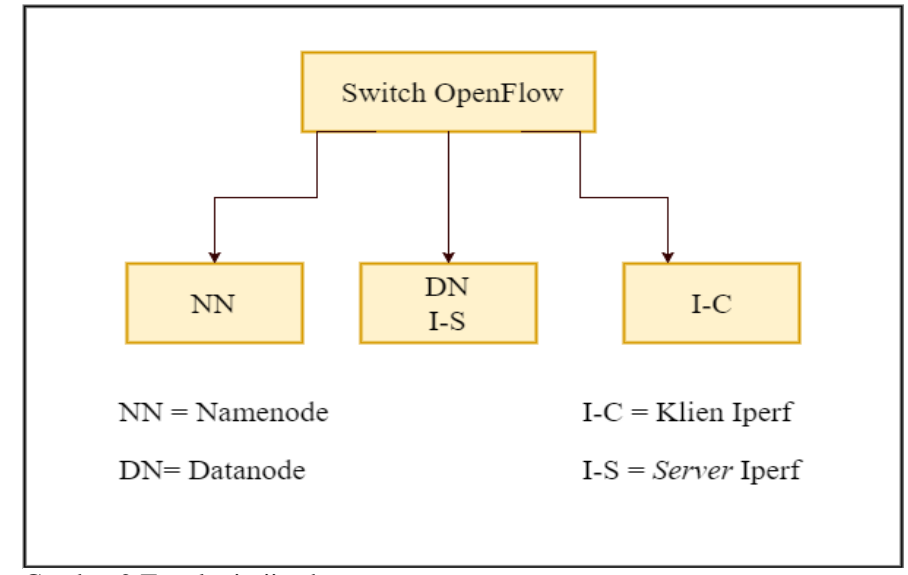

Gambar 2 Topologi uji coba

Pada skenario uji coba 1 proses penyimpanan data ke HDFS dilakukan tanpa diberikan traffic tambahan. Semua data masuk kedalam qo. Tujuan dari skenario uji coba 1 untuk mendapat nilai tolak ukur proses penyimpanan data ke HDFS. Data dimasukan dari Namenode kemudian data dikirimkan ke Datanode.

Hasil dari skenario 1 dapat dilihat pada Tabel 1. Berdasarkan hasil uji coba rata-rata waktu yang dibutuhkan untuk memasukan data sebesar 1MB kedalam HDFS 32 detik. Untuk data sebesar $10 \mathrm{MB}$ dan juga $20 \mathrm{MB}$ dibutuhkan waktu 5 menit 23 detik dan 11 menit 5 detik.

Tabel 1.

Hasil uji coba uji coba skenario 1

\begin{tabular}{cccccc}
\hline \hline Ukuran & \multicolumn{5}{c}{ Waktu (Menit:Detik) } \\
\hline $1 \mathrm{MB}$ & $00: 34$ & $00: 33$ & $00: 33$ & $00: 30$ & $00: 30$ \\
$10 \mathrm{MB}$ & $05: 43$ & $05: 22$ & $05: 23$ & $05: 09$ & $05: 21$ \\
$20 \mathrm{MB}$ & $10: 55$ & $11: 29$ & $11: 00$ & $11: 02$ & $11: 03$ \\
\hline \hline
\end{tabular}

\section{B. Skenario Uji Coba 2}

Skenario kedua pada saat menjalankan proses HDFS Hadoop diberikan lalu lintas tambahan yang berjalan pada queue yang sama. Pemberian lalu lintas tambahan dengan cara klien Iperf mengirimkan data berupa TCP ke Datanode sehingga lalu lintas data masuk ke Datanode terdapat congestion. Tujuan dari skenario ini untuk mendapatkan waktu apabila pada proses HDFS terdapat lalu lintas tambahan yang mengakibatkan congestion apabila lalu lintas data digabung tidak dilakukan manajemen transfer rate.

Hasil dari skenario 2 dapat dilihat pada Tabel 2. Berdasarkan hasil uji coba rata-rata waktu yang dibutuhkan untuk memasukan data sebesar 1MB kedalam HDFS 53 detik. Untuk data sebesar $10 \mathrm{MB}$ dan juga $20 \mathrm{MB}$ dibutuhkan waktu 7 menit 18 detik dan 13 menit 21 detik.

Tabel 2

Hasil uji coba skenario 2

\begin{tabular}{cccccc}
\hline \hline Ukuran & \multicolumn{5}{c}{ Waktu (Menit:Detik) } \\
\hline $1 \mathrm{MB}$ & $00: 52$ & $00: 55$ & $00: 51$ & $00: 52$ & $00: 55$ \\
$10 \mathrm{MB}$ & $07: 04$ & $07: 26$ & $07: 17$ & $07: 17$ & $07: 25$ \\
$20 \mathrm{MB}$ & $13: 11$ & $13: 30$ & $13: 25$ & $13: 27$ & $13: 12$ \\
\hline \hline
\end{tabular}

\section{Skenario Uji Coba 3}

Skenario uji coba 3 sama seperti skenario uji coba 2 dimana pada saat melakukan proses penyimpanan data ke HDFS dari Namenode menuju Datanode diberikan lalu lintas data tambahan yang dilakukan dengan menjalankan program Iperf server pada Datanode Iperf klien akan mengirimkan data juga menju Datanode sehingga lalu lintas data menuju Datanode terdapat congestion. Namun pada uji coba 3 dilakukan manajemen transfer rate. Lalu lintas data program Iperf dipisahkan dengan lalu lintas penyimpanan data ke HDFS. Lalu lintas program Iperf dimasukan ke dalam $q_{1}$ dan lalu lintas data HDFS dimasukan ke $q_{0}$. $Q_{0}$ diberikan nilai transfer rate yang lebih besar dari nilai transfer rate $q_{1}$. Pengaturan queue dapat dilihat pda Tabel 3. $Q_{0}$ diberikan nilai minimum transfer rate sebesar $800 \mathrm{Kbps}$ dan nilai maksimum sebesar $1 \mathrm{Mbps}$, dengan mengimplementasikan aplikasi manajemen transfer rate pada arsitektur yang dibangun dipastikan nilai transfer data untuk proses HDFS sesuai dengan nilai maksimum dan juga nilai minimum yang ditentukan.

Tabel 3

Pengaturan queue

\begin{tabular}{ccc}
\hline \hline Queue & Nilai maksimum & Nilai minimum \\
\hline $\mathrm{q}_{0}$ & $1 \mathrm{Mbps}$ & $800 \mathrm{Kbps}$ \\
$\mathrm{q}_{1}$ & $300 \mathrm{Kbps}$ & - \\
\hline \hline
\end{tabular}


Hasil dari skenario 3 dapat dilihat pada Tabel 4. Berdasarkan hasil uji coba rata-rata waktu yang dibutuhkan untuk memasukan data sebesar 1MB kedalam HDFS 35 detik. Untuk data sebesar $10 \mathrm{MB}$ dan juga $20 \mathrm{MB}$ dibutuhkan waktu 5 menit 31 detik dan 11 menit 25 detik.

Tabel 4

Hasil uji coba skenario 3

\begin{tabular}{cccccc}
\hline \hline Ukuran & \multicolumn{5}{c}{ Waktu (Menit:Detik) } \\
\hline $1 \mathrm{MB}$ & $00: 35$ & $00: 35$ & $00: 35$ & $00: 36$ & $00: 34$ \\
$10 \mathrm{MB}$ & $05: 44$ & $05: 30$ & $05: 25$ & $05: 25$ & $05: 33$ \\
$20 \mathrm{MB}$ & $11: 23$ & $11: 23$ & $11: 52$ & $10: 54$ & $11: 34$ \\
\hline \hline
\end{tabular}

\section{Evaluasi Uji Coba}

Berdasarkan hasil uji coba ketiga skenario yang dapat dilihat pada Gambar 3, skenario uji coba 2 membutuhkan waktu terbanyak untuk proses penyimpanan data HDFS. Sedangkan skenario uji coba 1 dan skenario uji coba 3 memiliki waktu proses yang hamper sama. Proses HDFS mengalami peningkatan waktu apabila terdapat lalu lintas tambahan pada cluster Hadoop, hal tersebut dapat dilihat dari perbandingan skenario satu dan dua dengan munculnya lalu lintas tambahan maka terjadi congestion yang dapat mempengaruhi waktu proses penyimpanan ke dalam HDFS. Melakukan manajemen transfer rate pada cluster Hadoop dapat menurukan waktu proses HDFS hal tersebut dapat dilihat dari perbandingan skenario dua dan tiga. Dengan melakukan manajemen transfer rate waktu proses HDFS Hadoop menjadi tidak terlalu banyak peningkatan walaupun dalam cluster Hadoop terdapat lalu lintas tambahan yang dapat mengakibatkan congestion.

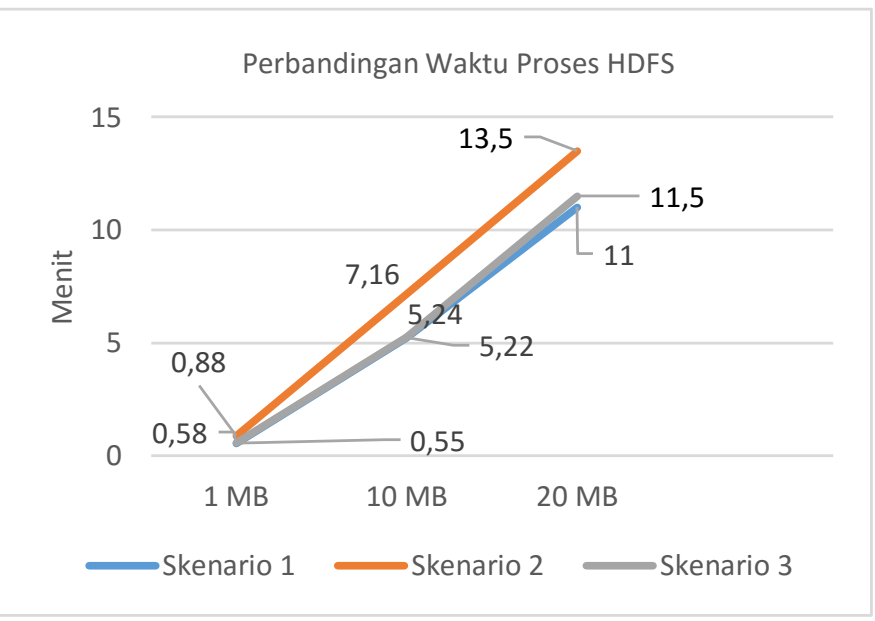

Gambar 3 Grafik perbandingan waktu HDFS

\section{KESIMPULAN DAN SARAN}

Berdasarkan hasil uji coba dan analisis, terdapat kesimpulan dan saran.

\section{A. Kesimpulan}

Dari hasil selama proses perancangan, implementasi, serta pengujian dapat diambil kesimpulan sebagai berikut:

1. Melakukan manajemen transfer rate dapat mengoptimalkan proses HDFS Hadoop pada cluster Hadoop.

2. Dengan menetapkan nilai transfer rate pada cluster Hadoop maka lalu lintas untuk proses penyimpanan data ke HDFS terbebas dari congestion yang disebabkan dari lalu lintas data lain.

3. Manajemen transfer rate dapat dilakukan dengan memanfaatkan fitur queue yang dimiliki switch Openflow.

4. Arsitektur SDN dapat dibangun dengan memanfaatkan Raspberry Pi sebagai switch Openflow untuk keperluan uji coba.

\section{B. Saran}

Saran yang dapat diberikan dalam pengujian sistem ini adalah sebagai berikut:

1. Melakukan pengaturan transfer rate dapat dilakukan secara dinamis.

2. Mekanisme konfigurasi perangkat memakan waktu yang lama dan berulang dapat dilakukan dengan menggunakan script.

\section{DAFTAR PUSTAKA}

[1] Open networking foundation, "Software-Defined Networking: The New Norm for Networks," 2014.

[2] T. White, Hadoop The Definitive Guide, California: O'REILLY, 2009.

[3] Open networking foundation, "SDN Architecture," 2014.

[4] McKeown, Nick; Anderson, Tom; Balakrishnan, Hari; Parulkar, Guru; Peterson, Larry; Rexford, Jennifer; Shenker, Scott; Turner, Jonathan, "Openflow; Enabling Innovation in Campus Networks," 14 March 2008.

[5] H. Kim, J. Kim and Y.-B. Ko, "Developing Cost-effective Openflow Test Bed for Small Scale Software Defined networking," 2014.

[6] "Ryu," [Online]. Available: http://github.com/osrg/ryu. [Accessed 10 Juni 2016].

[7] S. Narayan, S. Bailey and A. Daga, "Hadoop Acceleration in an Openflow based cluster," November 2012. 